\title{
Bulk Behavior vs Interface Adsorption: Specific Multivalent Cation and Anion Effects on BSA Interactions
}

\author{
Madeleine R. Fries, ${ }^{\dagger}$ Nina F. Conzelmann,$^{\dagger}$ Luzie Günter, ${ }^{\dagger}$ Olga Matsarskaia, ${ }^{\ddagger}$ \\ Maximilian W. A. Skoda, ${ }^{\Uparrow}$ Robert M. J. Jacobs, ${ }^{\S}$ Fajun Zhang, ${ }^{\dagger}$ and Frank \\ Schreiber*,,$\|$ \\ †Institute for Applied Physics, University of Tübingen, 72076 Tübingen, Germany \\ $\ddagger$ Institut Max von Laue - Paul Langevin (ILL), CS20156, F-38042, Grenoble, France \\ ๆISIS Facility, STFC, Rutherford Appleton Laboratory, Didcot, Oxon OX11 0QX, United \\ Kingdom \\ $\S$ Department for Chemistry, University of Oxford, Oxford, OX1 3TA, United Kingdom \\ \|Center for Light-Matter Interaction, Sensors $\&$ Analytics LISA+ ${ }^{+}$, University of Tübingen, \\ 72076 Tübingen, Germany \\ E-mail: frank.schreiber@uni-tuebingen.de
}

Experimental procedures and additional experimental data supporting the main findings of this paper are explained in the following. The Supporting Information are structured as follows:

Sections: S1 to S4

Pages: S1 to S9

Figures: $\mathrm{S} 1$ to $\mathrm{S} 6$

Table: S1 


\section{S1. Phase Behavior Determination}

The phase diagrams were determined by visual inspection and, for low $c_{\mathrm{p}}$, via UV-vis transmittance measurements due to faint visual turbidity. Previous studies have shown that the determination by visual inspection is sufficient and comparable to laser transmittance measurements. ${ }^{1}$ Examples are given for each salt in Figures S1a and b. At 1, 2, and $5 \mathrm{mg} / \mathrm{ml}$ $c_{\mathrm{p}}$, additional UV-vis measurements were performed with a Cary $50 \mathrm{UV}$-visible spectrometer (Varian Technologies, USA) (software: Scan) to determine $c^{*}$, when visual detection was not possible due to only faint changes in turbidity. The corresponding transmittance measurements for BSA with $\mathrm{LaI}_{3}$ and $\mathrm{YI}_{3}$ are given in Figure $\mathrm{S} 2$ and the respective values of $c^{*}$ are listed in Table S1. In the transmittance measurements, $c^{*}$ is defined by the first drop in the transmittance signal. For our systems, the method of choice to study LLPS formation is optical microscopy to see the droplet and network formations with examples given in Figure S1c. Images were taken with the Axio-Cam ICc5 in combination with an Axio Scope.A1 microscope by Carl Zeiss AG, which was operated with the software ZEN Lite 2012.

In Figure S3, the BSA phase diagram in the presence of nitrate salts are illustrated and modified from ref. 2. Here, re-entrant condensation vanishes for sufficiently high concentrations of $\mathrm{La}\left(\mathrm{NO}_{3}\right)_{3}$ and completely for $\mathrm{Y}\left(\mathrm{NO}_{3}\right)_{3}$.

Table S1: Phase transitions. $c^{*}$ values determined from UV-vis transmittance measurements shown in Figure S2.

\begin{tabular}{|c|c|c|}
\hline$c_{\mathrm{p}}[\mathrm{mg} / \mathrm{ml}]$ & $c_{\mathrm{s}}\left(\mathbf{Y I}_{3}\right)[\mathrm{mM}]$ & $c_{\mathrm{s}}\left(\mathrm{LaI}_{3}\right)[\mathrm{mM}]$ \\
\hline 1 & 1 & 5 \\
\hline 2 & 0.2 & 0.3 \\
\hline 5 & 0.4 & 0.5 \\
\hline
\end{tabular}




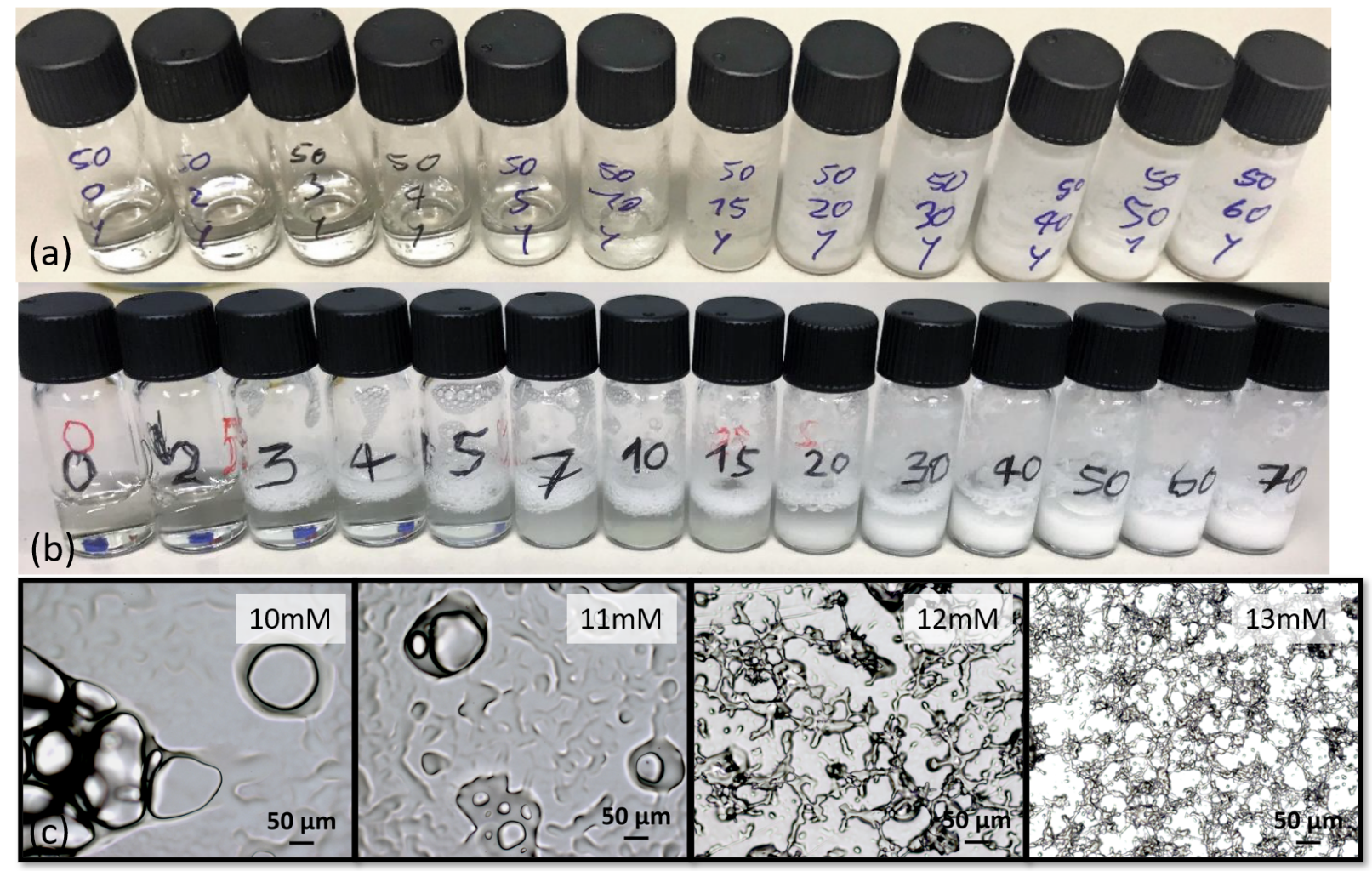

Figure S1: Phase transitions. Determination of phase transition by visual inspection of $50 \mathrm{mg} / \mathrm{ml} \mathrm{BSA}$ at room temperature with (a) $\mathrm{YI}_{3}$ and (b) $\mathrm{LaI}_{3}$ one day after preparation. The bottles are labeled with the respective $c_{\mathrm{s}}$ and with the respective $c_{\mathrm{p}}$ (only in (a)). The occurrence of LLPS was determined by optical microscopy. Examples are given for $50 \mathrm{mg} / \mathrm{ml}$ BSA in the presence of $\mathrm{LaI}_{3}$ with $c_{\mathrm{s}}$ between 10 to $13 \mathrm{mM}$ in (c). 

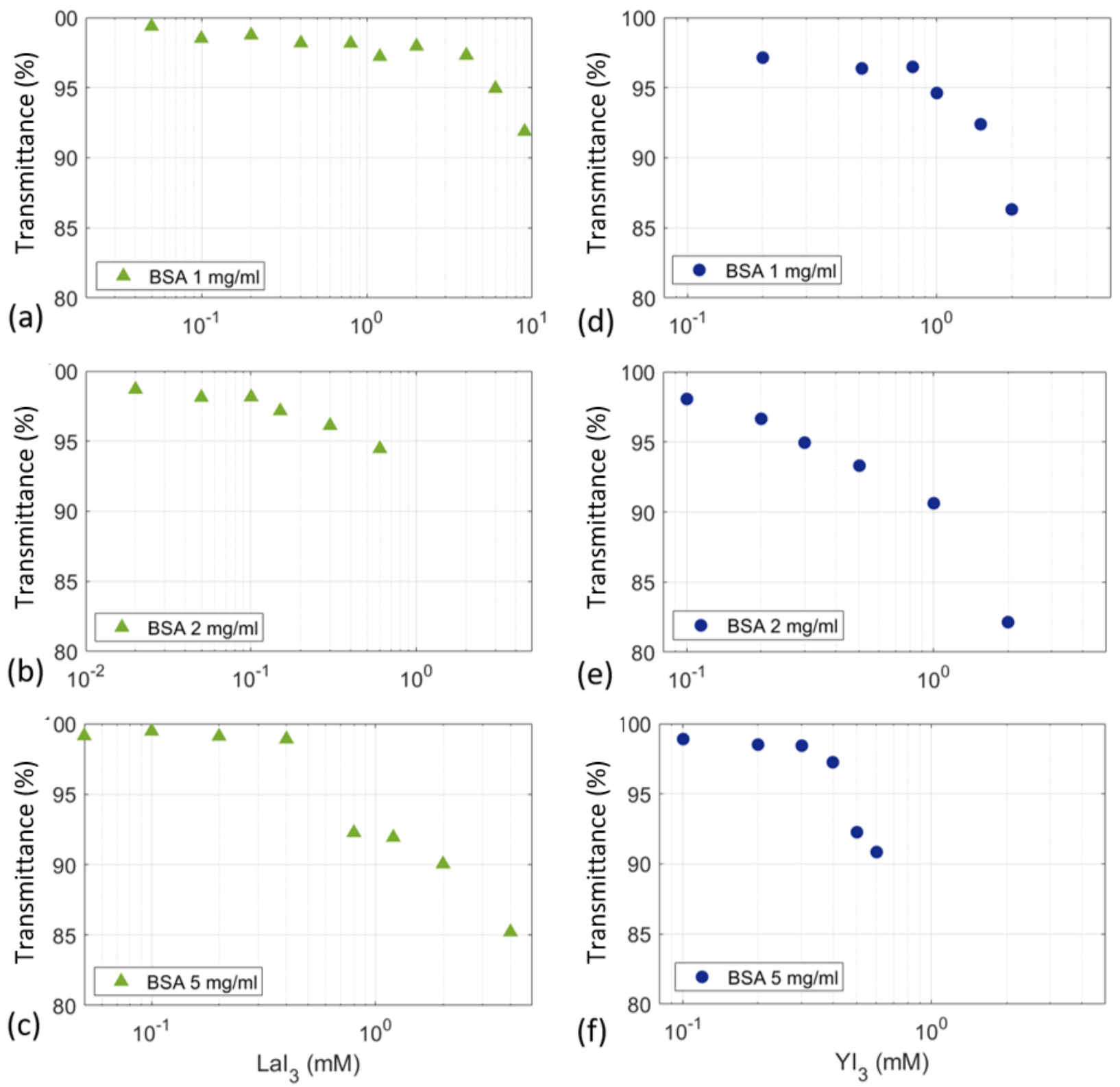

Figure S2: Transmittance measurements. UV-vis measurements of (a-c) $\mathrm{YI}_{3}$ at 1, 2, and $5 \mathrm{mg} / \mathrm{ml} \mathrm{BSA}$ and (d-f) for $\mathrm{LaI}_{3}$ at 1,2 , and $5 \mathrm{mg} / \mathrm{ml}$ BSA. The $c^{*}$ values determined from the UV-vis transmittance measurements are given in Table S1. 

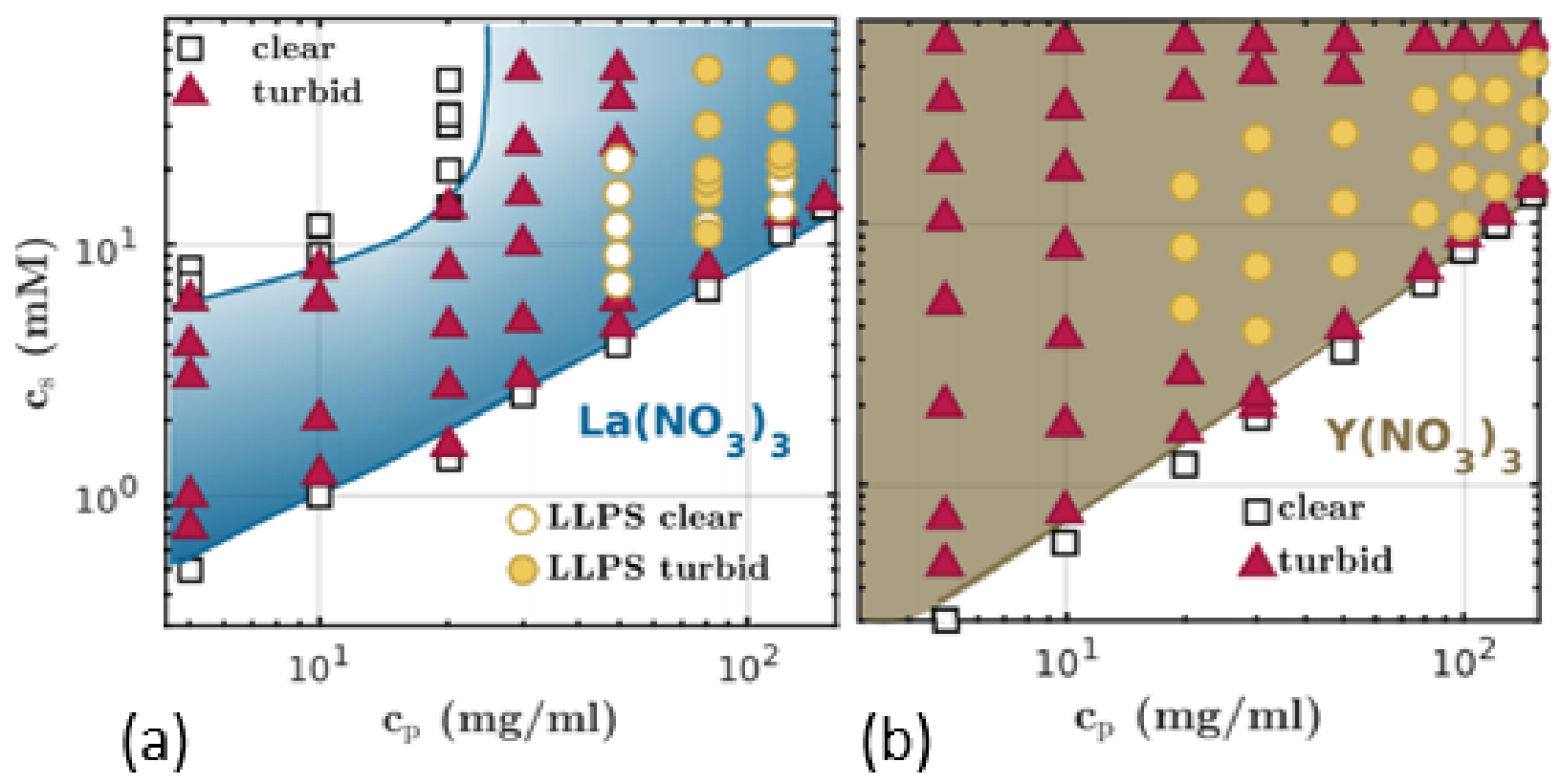

Figure S3: BSA phase diagram in the presence of nitrate salts. (a) Phase behavior of BSA with $\mathrm{La}\left(\mathrm{NO}_{3}\right)_{3}$ and $(\mathrm{b})$ with $\mathrm{Y}\left(\mathrm{NO}_{3}\right)_{3}$. Depending on the salt type, BSA undergoes different phase transitions. All salts induce LLPS (round markers). In the presence of $\mathrm{La}\left(\mathrm{NO}_{3}\right)_{3}$ the system undergoes partial re-entrant condensation, whereas BSA in the presence of $\mathrm{Y}\left(\mathrm{NO}_{3}\right)_{3}$ remains in regime II even at high $c_{\mathrm{s}}$. The images are modified from ref. 2. 


\section{S2. FTIR Measurements}

FTIR transmittance measurements cover a wave number range from 800 to $4000 \mathrm{~cm}^{-1}$. In Figure $\mathrm{S} 4$, the absorbance spectra of $\mathrm{BSA} / \mathrm{LaI}_{3}$ covering this entire wave number range are plotted. The difference in peak intensity is due to incomplete subtraction of the $\mathrm{D}_{2} \mathrm{O}$ signal.

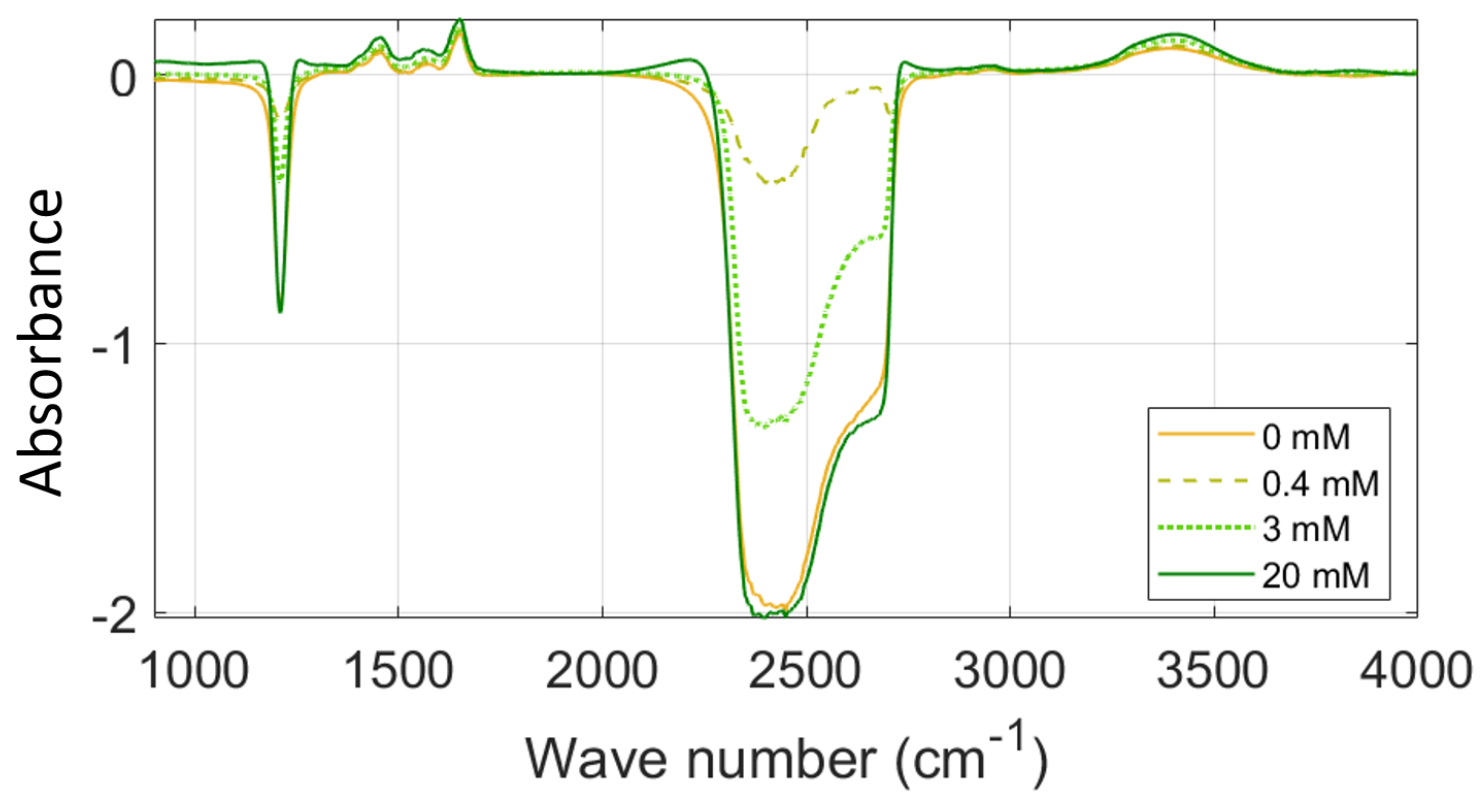

Figure S4: Full absorbance spectrum. FTIR transmittance measurements of the $\mathrm{BSA} / \mathrm{LaI}_{3}$ system at $c_{\mathrm{p}}=20 \mathrm{mg} / \mathrm{ml}$ in $\mathrm{D}_{2} \mathrm{O}$ at $20^{\circ} \mathrm{C}$. The measurements cover all regimes showing no significant changes in the amide-I band $\left(1600\right.$ to $\left.1700 \mathrm{~cm}^{-1}\right)$ at $c_{\mathrm{s}}$ of $0,0.4,3$, and $20 \mathrm{mM}$. The slight differences in peak intensity and position are due to incomplete $\mathrm{D}_{2} \mathrm{O}$ subtraction from transmittance measurements.

\section{S3. Dilute Phase}

$c_{\mathrm{p}}$ of the dilute phases of all samples at $20 \mathrm{mg} / \mathrm{ml} \mathrm{BSA}$ with $\mathrm{LaI}_{3}$ and $\mathrm{YI}_{3}$ were determined via UV-vis spectroscopy by applying the Beer-Lambert law and are plotted in Figure S5. This method is used because $c_{\mathrm{p}}$ of the dense phase is difficult to determine due to its high viscosity. Since we use a specific protein concentration and because of mass conservation we know that the lower $c_{\mathrm{p}}$ is in the dilute phase, the more proteins are found in the dense phase through strong aggregation and sedimentation. Thus, in combination with the volume of the 
dense phase increasing with increasing $c_{\mathrm{s}}$ shown in Figures $\mathrm{S} 1 \mathrm{a}$ and $\mathrm{b}$, it is obvious that the attractive interactions still increase with increasing $c_{\mathrm{s}}$ and that no re-entrant condensation can occur. The difference in $c_{\mathrm{p}}$ of the dilute phase between the two salts can be explained by weaker attractive interactions with $\mathrm{LaI}_{3}$ compared to $\mathrm{YI}_{3}$.

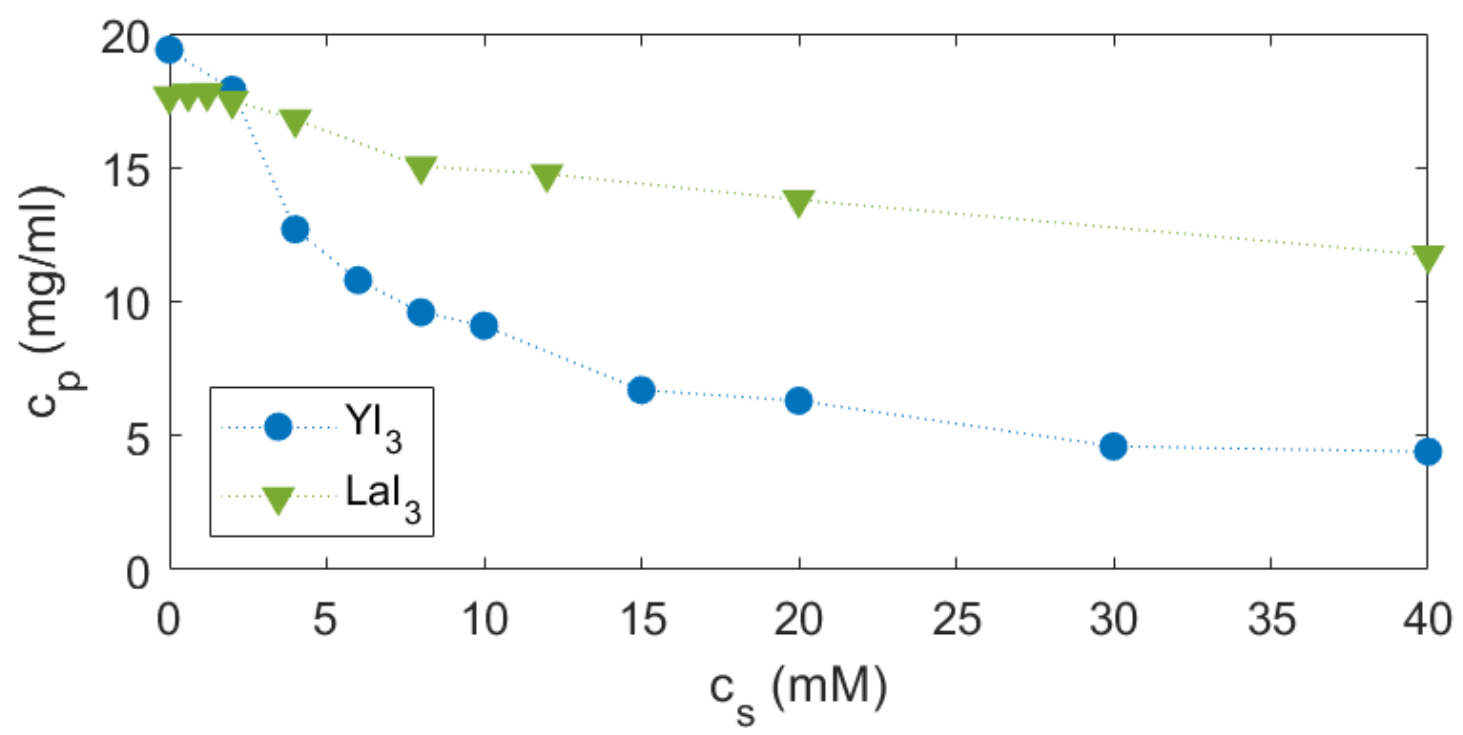

Figure S5: Dilute phase protein concentration. The samples were prepared at a BSA concentration of $20 \mathrm{mg} / \mathrm{ml}$ and only the dilute phase was measured by UV-vis spectroscopy. For $\mathrm{YI}_{3}, c_{\mathrm{p}}$ decreases with increasing $c_{\mathrm{s}}$, which illustrates stronger protein aggregate formation in the dense phase compared to $\mathrm{LaI}_{3}$.

\section{S4. ATR-FTIR}

To account for the bulk contribution to the adsorption signal and the difference between the structure of the adsorbed proteins compared to those in the bulk solution, the samples were measured in real-time in protein solution and rinsed with water after $30 \mathrm{~min}$ (Figure S6). We can conclude from the intensity differences that at some concentrations there is a strong bulk contribution to the measured intensity signal, yet the difference between protein structure in bulk and at the interface is non-existent (same curve progression). We can thus use the ATR-FTIR spectra in protein solution for our analysis and interpretation. 

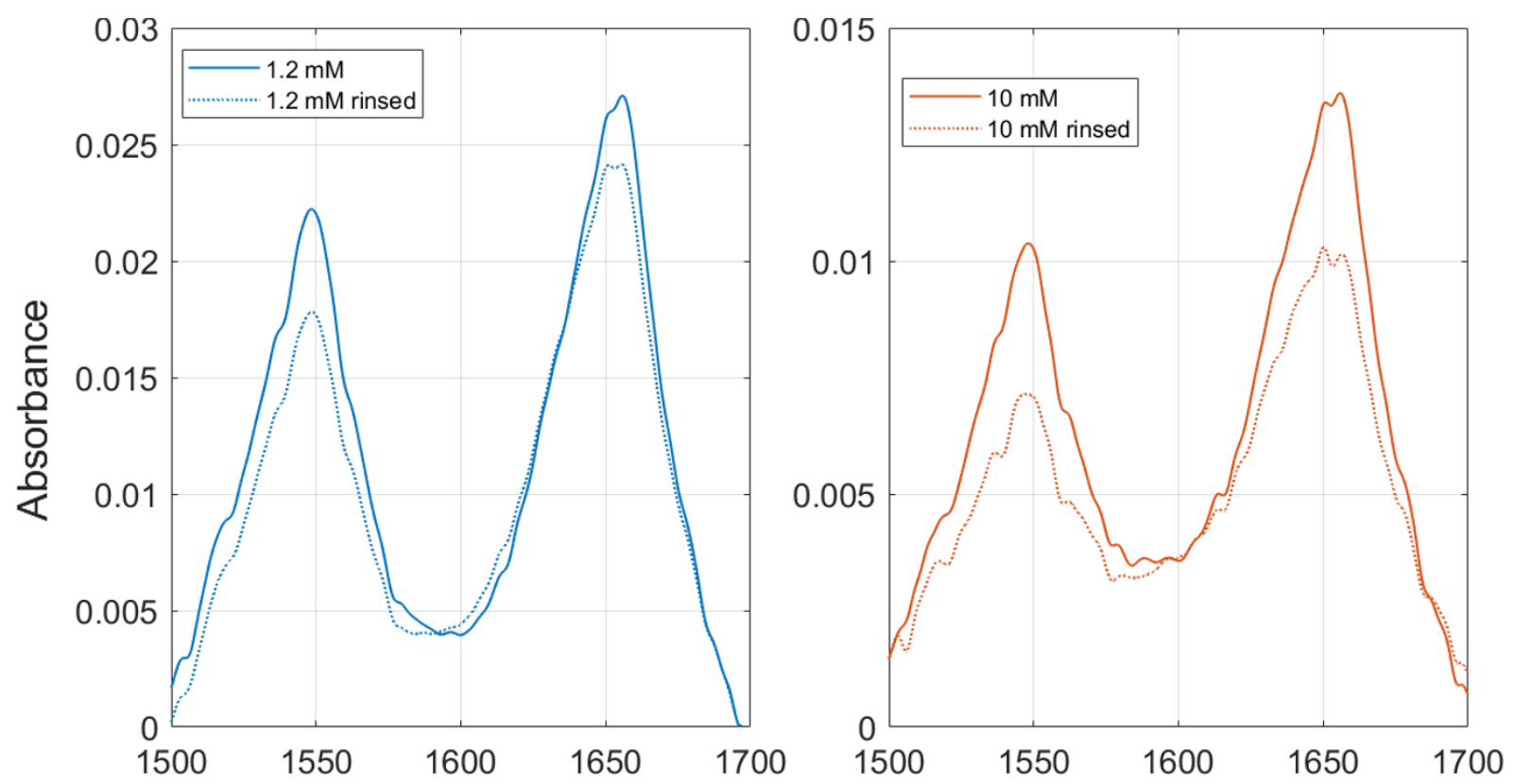

(a) $\mathrm{LaCl}_{3} \quad$ Wave number $\left(\mathrm{cm}^{-1}\right)$

(b) $\mathrm{LaCl}_{3} \quad$ Wave number $\left(\mathrm{cm}^{-1}\right)$
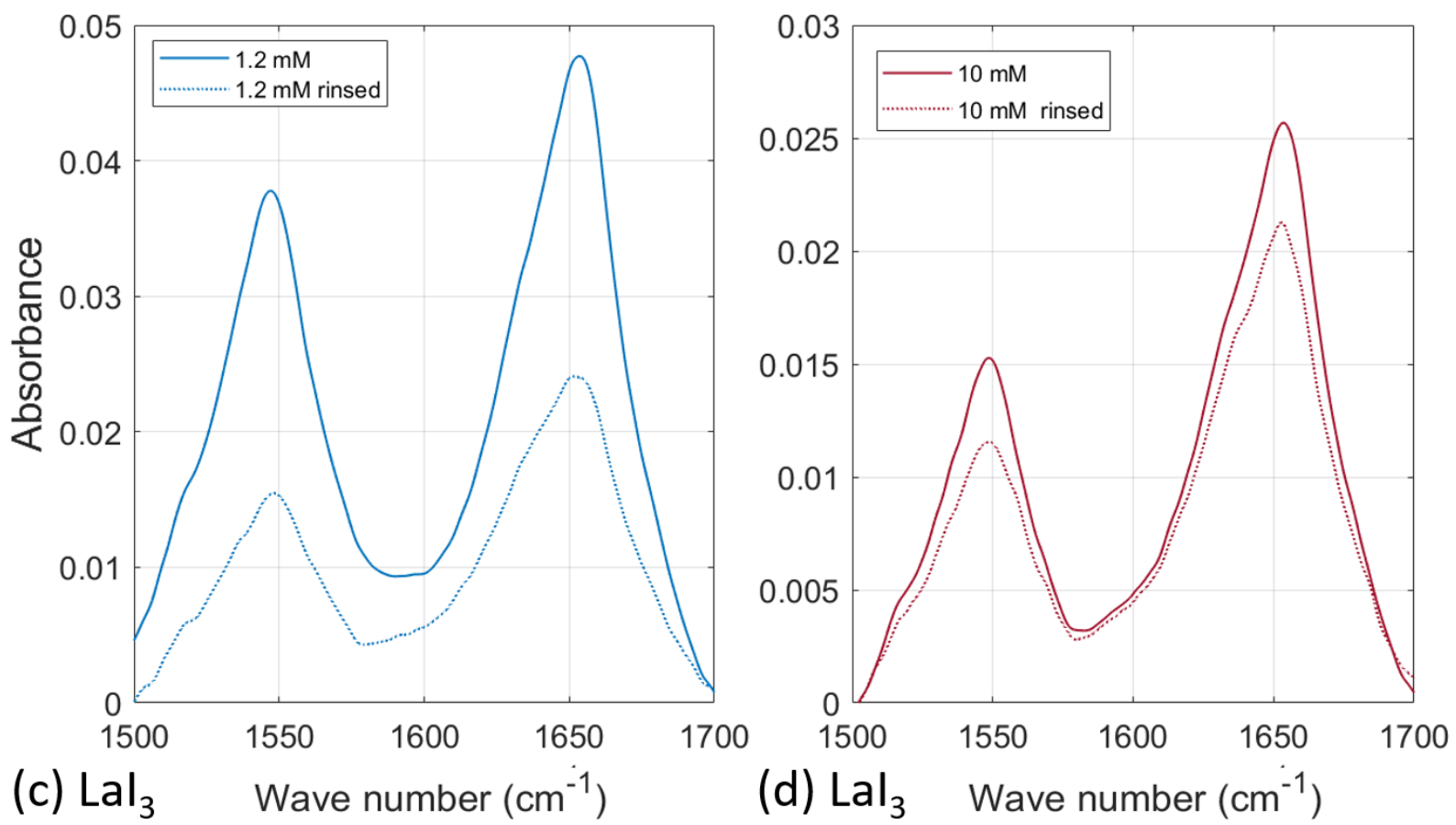

Figure S6: Protein interface signal vs bulk signal. Protein adsorption measurements studied by ATR-FTIR at RT for $5 \mathrm{mg} / \mathrm{ml} \mathrm{BSA}$ and $\mathrm{LaCl}_{3}$ at (a) $1.2 \mathrm{mM}$, (b) $10 \mathrm{mM}$, and $\mathrm{LaI}_{3}$ at (c) $1.2 \mathrm{mM}$ and (d) $10 \mathrm{mM}$. The solid lines depict the measured absorbance signal in the protein solution containing bulk and interface signal. The dotted lines show the sample rinsed with water, and thus, only depict the signal of the irreversibly adsorbed proteins. 


\section{References}

(1) Zhang, F.; Skoda, M. W. A.; Jacobs, R. M. J.; Zorn, S.; Martin, R. A.; Martin, C. M.; Clark, G. F.; Weggler, S.; Hildebrandt, A.; Kohlbacher, O.; Schreiber, F. Reentrant condensation of proteins in solution induced by multivalent counterions. Phys. Rev. Lett. 2008, 101, 148101.

(2) Braun, M. K.; Sauter, A.; Matsarskaia, O.; Wolf, M.; Roosen-Runge, F.; Sztucki, M.; Roth, R.; Zhang, F.; Schreiber, F. Reentrant phase behavior in protein solutions induced by multivalent salts: strong effect of anions $\mathrm{Cl}^{-}$versus $\mathrm{NO}_{3}^{-}$. J. Phys. Chem. B 2018, 122, 11978-11985. 